\title{
Physical Mapping and Chromosomal Location of the Photoperiod Response Gene Ppd2 in Common Wheat
}

\author{
Nikolay P. Goncharov*1) and Nobuyoshi Watanabe ${ }^{2)}$ \\ 1) Institute of Cytology and Genetics, Siberian Branch of the Russian Academy of Sciences, Lavrentiev Ave. 10, Novosibirsk, 630090, \\ Russia \\ 2) Faculty of Applied Biological Sciences, Gifu University, 1-1 Yanagido, Gifu 501-1193, Japan
}

\begin{abstract}
Duration from sowing to flowering is of critical importance for crop adaptation. Breeding for the optimal flowering time is one of the major factors, which confer maximal yields in a given environment. The timing of flowering is modulated primarily by responsiveness to photoperiod and temperature, and there are large differences in sensitivity among genotypes. In most spring wheat cultivars the duration of the vegetative period is strongly influenced by genes controlling photoperiod response. In this paper we report the photoperiod responses of a set of 'Chinese Spring' substitution and partial deletion lines of homoeologous group 2 chromosomes studied under natural short days. We confirmed the presence of dominant genes Ppdl and Ppd2 on chromosomes 2D and 2B, respectively, and compared the effects of $P p d l$ and $P p d 2$ for daylength response. The photoperiodic responses of partial chromosome deletion lines of 'Chinese Spring' allowed us to map $P p d 2$ physically between breakpoints 0.27 and 0.53 of the short arm of chromosome $2 \mathrm{~B}$. This result is consistent with the finding of a possible location of $P p d 2$ based on molecular marker studies. A dosage effect of the dominant gene $P p d 2$ was shown.
\end{abstract}

Key Words: Triticum aestivum, photoperiod response, $P p d 2$, physical mapping.

\section{Introduction}

Common wheat (Triticum aestivum L.) is a long-day plant and quantitatively responds to photoperiod (Garner and Allard 1923), i.e. the longer the period of light is, the earlier wheat plants flower. Wheat cultivars of low day length sensitivity are cultivated more successfully in lower latitudes compared to cultivars with high day length sensitivity (Razumov 1961). For several decades, it has been found that breeding for high yield and good adaptation were associated with decreased sensitivity to photoperiod (Davidson and Christian 1984). Thus, the modern cultivars of Mexico (the CIMMYT breeding program), India, Southern Europe and Japan are of lower day length sensitivity than their predecessors (Borlaug et al. 1964, Yoshida et al. 1983, Maystrenko and Aliev 1985, Worland and Sayers 1996).

Wheat cultivars vary from insensitive to highly sensitive in their photoperiod response. Keim et al. (1973) and Welsh et al. (1973) concluded that insensitivity to day length of spring wheat cv. 'Sonora 64' was controlled by two major genes and one or more gene-modifiers. It was confirmed that three genes control photoperiodic insensitivity in common wheat (Scarth and Law 1983, Merezhko 1984, Goncharov 1987).

Communicated by J. Michael Bonman

Received September 9, 2004. Accepted October 29, 2004.

*Corresponding author (e-mail: gonch@bionet.nsc.ru)
Monosomic analysis of a cross 'Cheyenne' with 'Sonora 64' showed that there were two major genes for insensitivity to short daylength: $P p d l$ located on chromosome 2D (Welsh et al. 1973, Pirasteh and Welsh 1975), and Ppd2 located on chromosome 2B (Welsh et al. 1973). It was hypothesized that a third dominant gene with a weaker effect was located on one of three chromosomes, $4 \mathrm{~A}^{*}$ (designated according to the $7^{\text {th }}$ IWGS), 7B or 6D (Pirasteh and Welsh 1975). Later a third gene, $P p d 3$, was located on chromosome 2A in 'Chinese Spring' by Law et al. (1978). However, the allelic relation of this gene to the gene described earlier as $P p d 3$ by Pirasteh and Welsh (1975) has not been determined. The dominant gene $P p d 2$ was located on the short arm of chromosome 2B (Boyd 1974, Law et al. 1978). Scarth and Law (1984) located genes $P p d 1$ and $P p d 3$ on the long arms of chromosomes 2D and 2A, respectively. However, using molecular markers Worland and Sayers (1996) and Korzun et al. (1998) indicated that the Ppdl gene is located on the short arm of chromosome 2D.

Law and Worland (1997) believed that dominant gene Ppdl originated in the Far East and was transferred through the Japanese cv. 'Akakomugi' to Italy. Worland and Sayers (1996) and Whitechurch and Slafer (2002) presumed that Ppdl is the primary gene controlling the weak photoperiod sensitivity of south-European common wheat cultivars and confers adaptation to the climatic conditions of southern Europe. Ppdl is also found in the cultivars bred in the CIMMYT breeding program. It is presently uncertain 
whether Ppd1 is present in Aegilops squarrosa L. (= syn. Ae. tauschii Cosson), the D genome donor of hexaploid wheat, although several accessions of this species have been studied (Gororo et al. 2001).

The origin of the dominant gene $P p d 2$, as well as its geographical distribution, is not clear, although its presence in 'Chinese Spring' and cultivars of CIMMYT breeding program suggests that it may be of Asian origin.

Most spring common wheat cultivars of mid-latitudes have photoperiod sensitivity (Razumov 1961). A dominant gene, probably $P p d 3$, with weak phenotypic effect is common among them (Aliev and Maystrenko 1986, Goncharov 1986).

The aims of this research were to study the photoperiod response of common wheat cv. 'Chinese Spring' and its substitution and partial chromosome deletion lines and to physically locate dominant gene $P p d 2$.

\section{Materials and Methods}

Chromosome substitution lines, tetrasomic lines and partial chromosome deletion lines

We considered only homoeologous group 2 substitution lines of 'Chinese Spring' (CS) since major Ppd genes controlling insensitivity to day length are located on chromosomes 2D and 2B in common wheat (Welsh et al. 1973). Substitution lines of CS/Ul'yanovka 2B, CS/Ciano F67 2D and $\mathrm{CS} /$ Lutescens $2 \mathrm{~B}$ were originally obtained from Dr. Z.B. Gulyaeva (Vavilov Institute of Plant Industry, St.-Petersburg, Russia) and Prof. C.N. Law (John Innes Centre, Norwich, UK).

In the 'Chinese Spring' chromosome substitution lines, a pair of homologous chromosomes was replaced with a pair of homologous chromosomes of the donor cultivar. For example, in the line CS/Ul'yanovka 2B, chromosome 2B of 'Chinese Spring' was replaced by chromosome 2B of cv. 'Ul'yanovka'. The Ppd-genotypes of the substitution lines were as follows: $p p d 1 p p d 1 \mathrm{Ppd} 2 \mathrm{Ppd} 2$ for 'Chinese Spring', ppdlppd1 ppd2ppd2 for CS/Ul'yanovka $2 \mathrm{~B}$ and CS/Lutescens 2B, and Ppd1Ppd1 Ppd2Ppd2 for CS/Ciano F67 2D.

Three tetrasomic lines of homeologous group 2 of 'Chinese Spring' $(2 n=44)$ produced by Dr. E.R. Sears (Univ. Missouri, Columbia, USA) were obtained from Dr. O.I. Maystrenko (Institute of Cytology and Genetics of Russian Acad. Sci., Novosibirsk, Russia).

Response to photoperiod was also estimated for three 'Chinese Spring' lines with partial deletions of the short arm of chromosome 2B produced by Endo and Gill (1996). These deletion lines are characterized by the fraction length (FL) values where the breaks occur (2BS-3, FL $=0.75$; $2 \mathrm{BS}$ $1, \mathrm{FL}=0.53 ; 2 \mathrm{BS}-11, \mathrm{FL}=0.27)$.

\section{Experiments}

The 'Chinese Spring' substitution lines were sown in October 1998, and three tetrasomic lines of 'Chinese Spring' and partial deletion lines were sown in October 1999. They were grown under natural short days in the experimental fields of Gifu University, Japan (35'27’30’'N, $\left.136^{\circ} 44^{\prime} 30^{\prime \prime} \mathrm{E}\right)$. Heading of spikes usually started from the middle of April in Gifu and April 1st was used as the arbitrary zero date. At least 10 plants were of each line were grown. Heading was recorded daily. We considered that the differences among lines in heading dates under short days would be conditioned by differences in the complement of $P p d$ genes, because substitution and deletion lines are different only in genes located either on chromosomes of homoeologous group 2 or over the fractions of the chromosome short arm 2B and they are of identical Vrn gene background. Thus, the differences in heading date could be simply attributed to day length response, because the combined effect of differences in Vrn and Ppd genes (Law and Worland $1997)$ on heading dates will be avoided. All three lines are spring and have dominant gene Vrn3 as cv. 'Chinese Spring' does (Goncharov 1986). The results were analyzed according to Student's test.

\section{Results}

The days to heading of the various lines in the three experiments are summarised in Table 1. We consider here the effect of Ppd1 and Ppd2 genes on the days to heading in three sets of experiments.

The heading time of cv. 'Chinese Spring' and its substitution lines are presented in Figure 1. CS/Ciano F67 2D was earliest among the lines. 'Chinese Spring' headed with a 7-day delay compared to the substitution line of CS/Ciano F67 2D $(\mathrm{t}=18.18(\mathrm{df}=42), \mathrm{P}<0.01)$. Substitution lines $\mathrm{CS} / \mathrm{Ul}$ 'yanovka $2 \mathrm{~B}$ and CS/Lutescens $622 \mathrm{~B}$ were devoid of the dominant gene $P p d 2$ and headed later (12 days and 5 days; $\mathrm{t}=11.07, \mathrm{df}=38$ and $\mathrm{t}=25.56, \mathrm{df}=38$, respectively. $\mathrm{P}<0.01$ ) than 'Chinese Spring'.

A considerable phenotypic effect of Ppdl on the expression of insensitivity to day length was also shown compared to $P p d 2$. There was a dosage effect of the dominant gene $P p d 2$ as shown by the lower photoperiod sensitivity of the tetrasomics ( 4 gene doses in the tetrasomic compared to 2 in the euploid) (Fig. 2) The tetrasomic 2B of Chinese Spring $(2 n=44)$ with four doses of the dominant gene Ppd2 was 2.5 days earlier than cv. 'Chinese Spring' $(\mathrm{t}=8.94(\mathrm{df}=$ $48), \mathrm{P}<0.01)$. Tetrasomic $2 \mathrm{D}$ of Chinese Spring $(2 n=44)$ was earlier heading than 'Chinese Spring'. Probably, the tetrasomic 2D of Chinese Spring has gene(s) with minor effect on chromosome 2D, which at four doses resulted in slightly earlier heading than 'Chinese Spring' $(\mathrm{t}=7.85(\mathrm{df}=$ 52), $\mathrm{P}<0.01)$. However the tetrasomic $2 \mathrm{~A}$ of Chinese Spring did not manifest the effect of four doses of chromosome $2 \mathrm{~A}$ on which $P p d 3$ with weak phenotypic effect is located.

Analysis of 'Chinese Spring' partial chromosome deletion lines permitted the physical mapping of dominant gene $P p d 2$. The heading data for the deletion lines of 'Chinese Spring' are presented in Figure 3. 
Table 1. Days to heading of the experimental lines under natural short days in Gifu, Japan

\begin{tabular}{llc}
\hline \hline Experiment and line & Genotype & Days to heading ${ }^{1} \pm$ s.e. \\
\hline Substitution lines ${ }^{2}$ & & \\
CS euploid & ppdlppd1 Ppd2Ppd2 & $25.4 \pm 0.21$ \\
CS/Ciano F67 2D & Ppd1Ppd1 Ppd2Ppd2 & $17.9 \pm 0.34$ \\
CS/Ul'yanovka 2B & ppdlppd1 ppd2ppd2 & $37.4 \pm 0.36$ \\
CS/Lutescens 62 2B & ppdlppd1 ppd2ppd2 & $30.6 \pm 0.39$ \\
Tetrasomic lines ${ }^{3)}$ & & \\
CS euploid & ppdlppd1 Ppd2Ppd2 & $28.2 \pm 0.18$ \\
Tetra 2A CS & ppdlppd1 Ppd2Ppd2 & $27.3 \pm 0.28$ \\
Tetra 2B CS & ppdlppd1 Ppd2Ppd2 Ppd2Ppd2 & $25.6 \pm 0.25$ \\
Tetra 2D CS & ppdlppd1 ppd1ppd1 Ppd2Ppd2 & $25.8 \pm 0.25$ \\
CS deletion lines ${ }^{3)}$ & & \\
CS euploid & ppdlppd1 Ppd2Ppd2 & $28.2 \pm 0.18$ \\
2BS-3 (0.75) & ppdlppd1 Ppd2Ppd2 & $30.4 \pm 0.65$ \\
2BS-1 (0.53) & ppdlppd1 Ppd2Ppd2 & $30.6 \pm 0.17$ \\
2BS-11 (0.27) & ppd1ppd1 & $35.4 \pm 0.33$ \\
\hline
\end{tabular}

1) April 1 was assumed as zero.

2) Scoring was done in 1999 .

3) Scoring was done in 2000.

Abbreviations: CS - 'Chinese Spring'

Numbers in parenthesis indicate the fraction length of short arm of chromosome 2B.

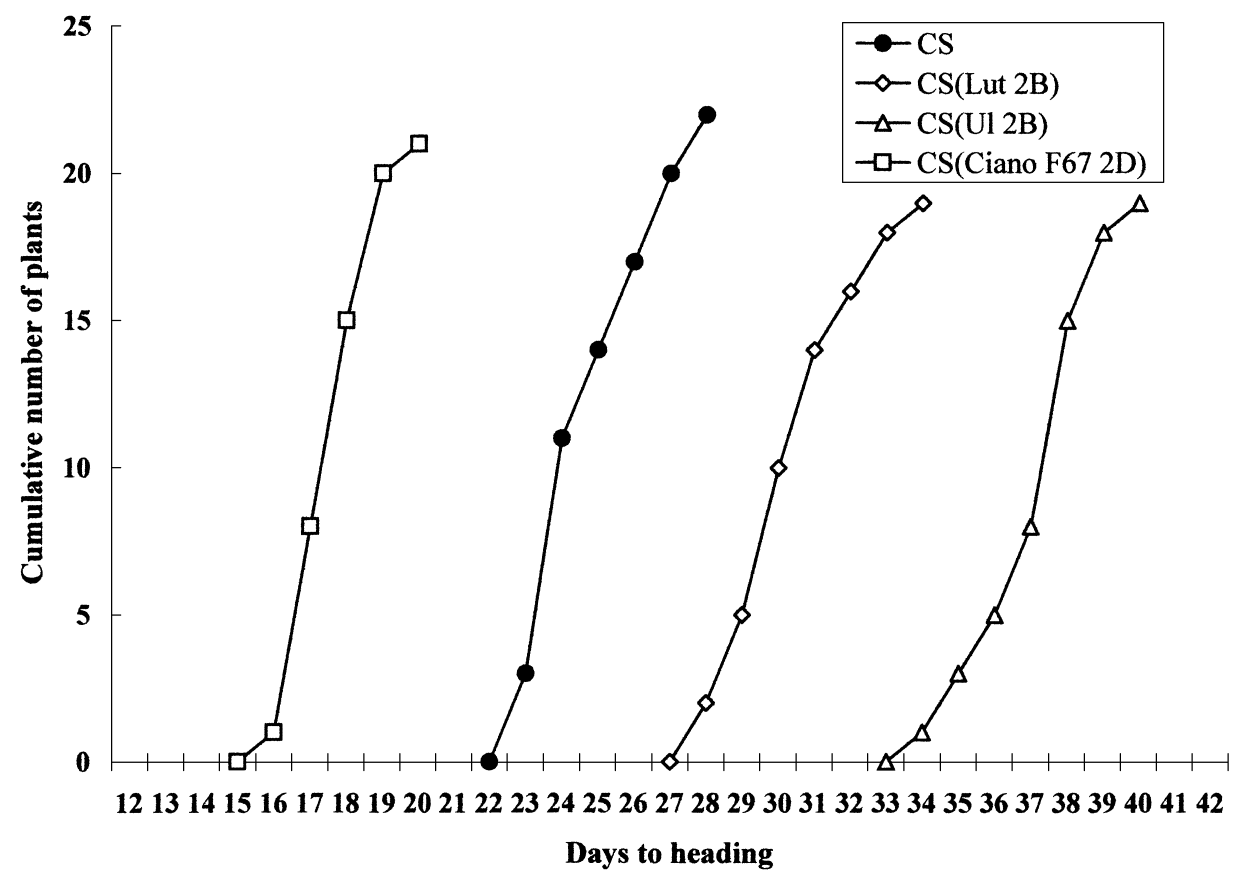

Fig. 1. Days to heading of 'Chinese Spring' and its substitution lines under natural short days in Gifu, Japan. Abbreviations: CS - 'Chinese Spring', Lut - 'Lutescens 62', U1 - 'Ul'yanovka'. Data are shown as accumulative number of plants for each lines.

Lines 2BS-1 $(\mathrm{FL}=0.53)$ and $2 \mathrm{BS}-3(\mathrm{FL}=0.75)$ did not differ significantly in their heading dates from that of cv. 'Chinese Spring' $(\mathrm{t}=1.41, \mathrm{df}=47$ and $\mathrm{t}=1.80, \mathrm{df}=38$, respectively. $\mathrm{P}<0.01)$. On the other hand, line 2BS-11 (FL= $0.27)$ was significantly different $(\mathrm{t}=5.36(\mathrm{df}=33) \mathrm{P}<0.01)$ from 'Chinese Spring'. The results suggest that $P p d 2$ is located between 0.53 and 0.27 break points on the short arm of chromosome 2B (Fig. 4).

\section{Discussion}

Scarth and Law $(1983,1984)$ showed that $P p d 2$ is located on the short arm of chromosome 2B. Using deletion lines, the region where gene $P p d 2$ is located, was found between 0.27 and 0.53 breakpoints on the short arm of chromosome 2B (Fig. 4). This result is consistent with the finding of possible location of $P p d 2$ based on molecular marker studies (Snape et al. 1996, Worland and Sayers 1996, Sourdille et al. 2000). 


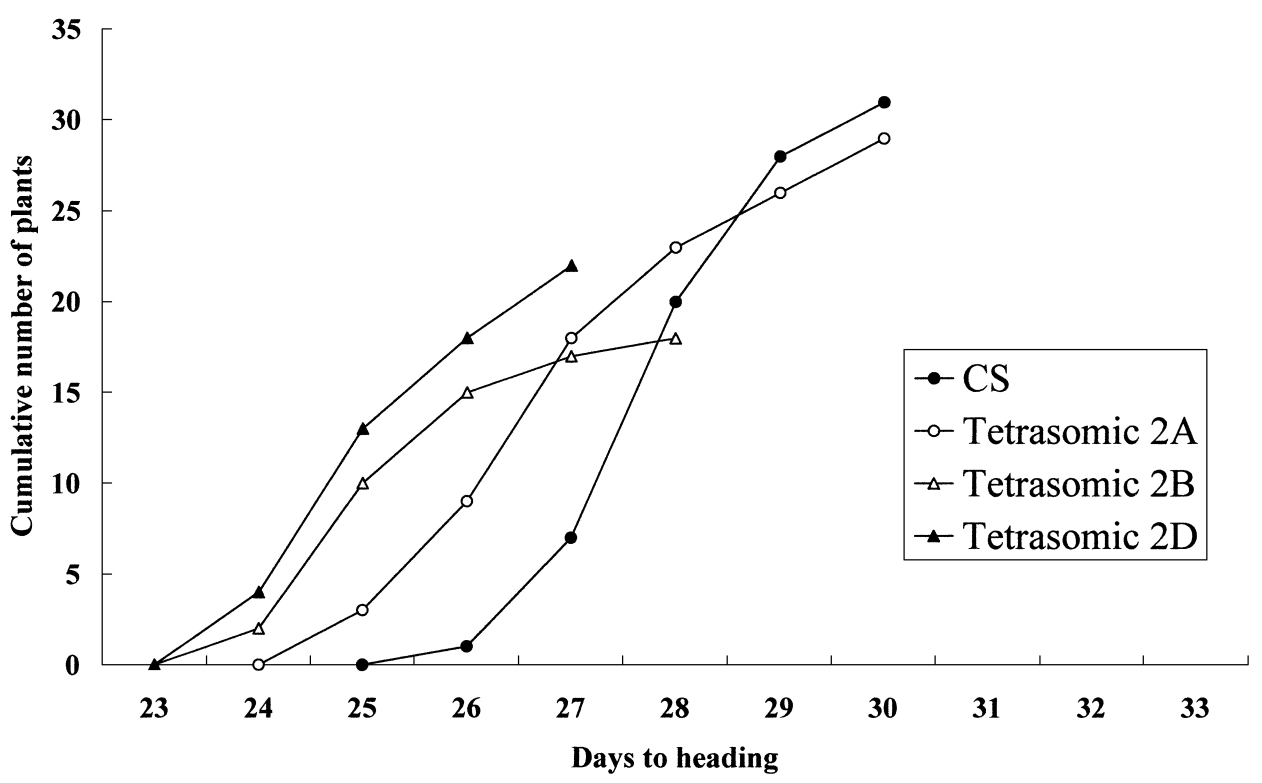

Fig. 2. Days to heading of 'Chinese Spring' (CS) and its tetrasomic lines under natural short days in Gifu, Japan. Data are shown as accumulative number of plants for each lines.

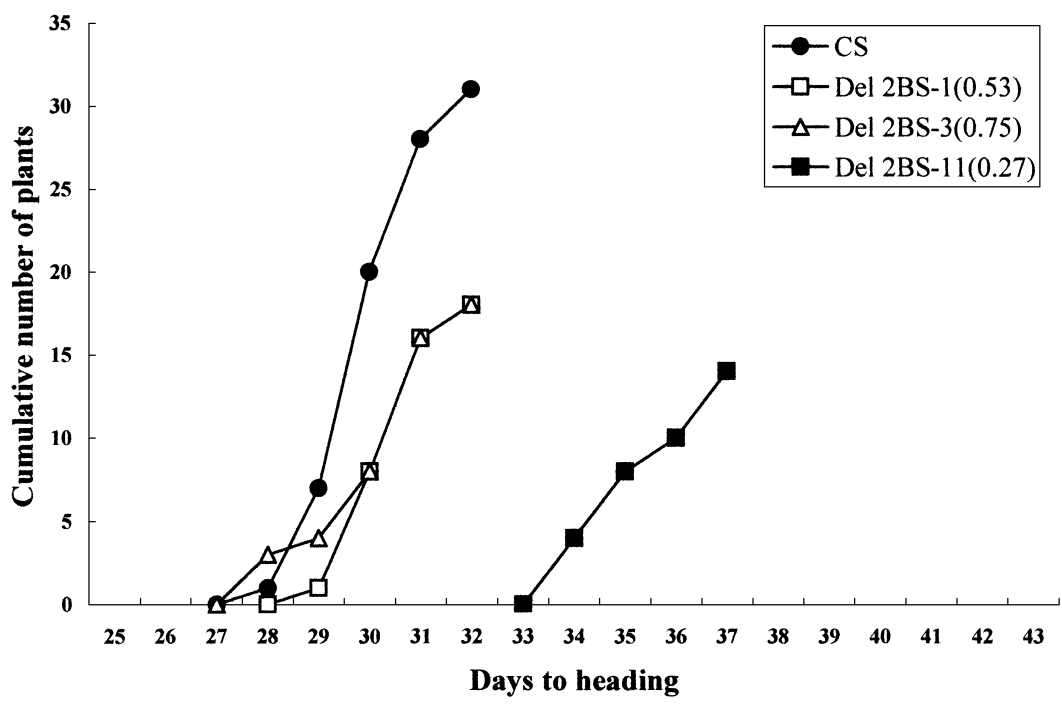

Fig. 3. Days to heading of partial chromosome 2B deletion lines (Del2BS) in the short arm of 'Chinese Spring' (CS) under natural short days in Gifu, Japan. Data are shown as accumulative number of plants for each lines.

Substitution and addition lines, including those with the chromosomes of related species (Scarth and Law 1984, Murai et al. 1997), are frequently used to study the effect of chromosomes on the expression of photoperiod response and duration of vegetation period (Scarth and Law 1983, Whitechurch and Slafer 2002, Foulkes et al. 2004). The location of $P p d 2$ in chromosome $2 \mathrm{~B}$ has been confirmed as shown in Figure 4. Our data agreed with that of Welsh et al. (1973) who found the presence of a dominant gene Ppdl in chromosome 2D of Mexican cultivars (Fig. 1). Ppdl strong accelerated flowering time in plants of substitution line CS/ Ciano F67 2D. The dosage effect of dominant gene Ppd2, which was found in the present study, confirms result of
Islam-Faridi et al. (1996). However, our findings differ from those of Hoogendoorn (1985), who did not reveal any dosage effect of dominant gene Ppd2. We also did not find any effect of four doses of chromosome 2A (Fig. 2). We suppose that the effect of Ppd gene on chromosome 2A of 'Chinese Spring' is extremely weak under field conditions. Chromosomal location of $P p d 3$ on chromosome $2 \mathrm{~A}$ was contradictory. Halloran and Boydell (1967), Zveinek (1983), Flood and Halloran (1984) and Whitechurch and Slafer (2001) did not find a significant effect of chromosome $2 \mathrm{~A}$ of 'Chinese Spring' substitution lines on photoperiod sensitivity, whereas Law et al. (1978) reported positive effects. Breeding for photoperiod sensitivity will be facilitated by using only 2 


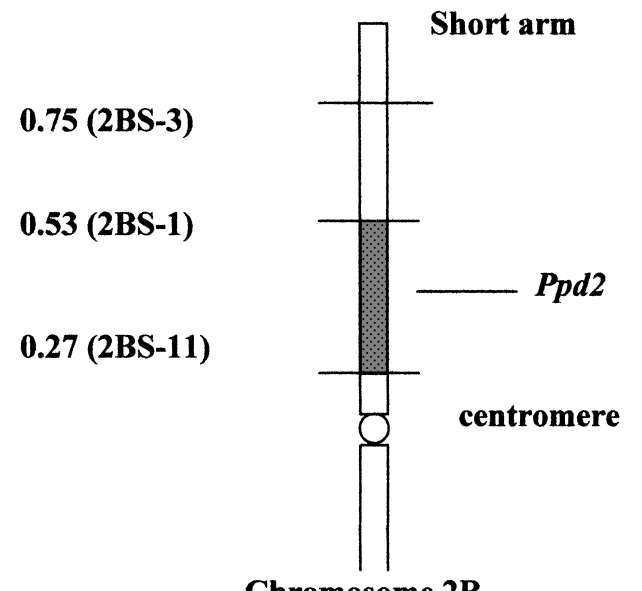

Chromosome 2B

Fig. 4. Physical map of the short arm of 'Chinese Spring' chromosome 2B. Fraction lengths (FL) and deletion stock number are indicated on the left of physical map. The chromosomal region from $\mathrm{FL}=0.27$ to $\mathrm{FL}=0.53$ shows the putative location of the $\operatorname{Ppd} 2$ gene.

dominant $P p d$ genes, namely $P p d 1$ and $P p d 2$, and, possibly, a number of minor genes controlling photoperiod response identified on several other chromosomes (Halloran and Boydall 1967, Islam-Faridi et al. 1996, Law et al. 1998). It may also be valuable to identify new dominant genes with strong phenotypic manifestation. Probably, some diploid wheat related species could be the sources of new dominant genes with strong phenotypic effect. Some accessions of Ae. squarrosa (= syn. Ae. tauschii) were earlier than accessions of genus Triticum (Goncharov and Chikida 1995).

Low photoperiod sensitivity is not the same as earliness and relatively insensitive cultivars could have later heading dates than more sensitive ones (Davidson and Christian 1984). This is typical of Mediterranean wheat cultivars with high vernalization response (Razumov 1961, Davidson and Christian 1984). It should also be noted that the lines with dominant alleles of Ppd genes are earlier under both short and long days (Goncharov 1986) and they affect ecological adaptability (Borlaug et al. 1964, Martinič 1973), number of leaves per stem (Goncharov 1986, Slafer and Rawson 1995) and other agronomically important traits in wheat (Lebsock et al. 1973, Worland et al. 1988, Börner et al. 1993, Merezhko 1994, Koshkin et al. 2004).

\section{Acknowledgements}

The author is grateful to Drs. Z.B. Gulyaeva (VIR, St.-Petersburg, Russia), C.N. Law (JIC, Norwich, UK), O.I. Maystrenko (ICG, Novosibirsk, Russia) and T.R. Endo (Kyoto Univ., Japan) who kindly provided different 'Chinese Spring' lines. NPG would also like to thank the Japan Society for the Promotion of Science (Grant ID No. S-00151) for the financial support of part of this investigation.

\section{Literature Cited}

Aliev,E.B. and O.I.Maystrenko (1986) A precise determination of a number of genes involved in photoperiod response in spring wheats with different sensitivity to natural short day light. Cereal Res. Commun. 14: 129-131.

Borlaug,N.E., J.Ortega, I.Narvaez, A.Garcia and R.Rodriques (1964) Hybrid wheat in perspective. In "Hybrid Wheat Seminar" Minneapolis, USA. p. 12-27.

Börner,A., A.J.Worland, J.Plashke, E.Shuman and C.N.Law (1993) Pleiotropic effects of genes for reduced height $(R h t)$ and daylength insensitivity (Ppd) on yield and its components for wheat growth in Middle Europe. Plant Breed. 111: 204-216.

Boyd,W.J.R. (1974) Studies with substitution lines. European Wheat Aneuploid Co-operative Newsl. 4: 66.

Davidson,J.L. and K.R.Christian (1984) Flowering in wheat. In "Control of Crop Productivity" Pearson,C.J. (ed.), Academic Press, Sydney. p. 112-126.

Endo,T.R. and B.S.Gill (1996) The deletion stocks of common wheat. J. Hered 87: 295-307.

Flood,R.G. and G.M.Halloran (1984) Temperature as a component of the expression of developmental response in wheat. Euphytica 33: 91-98.

Foulkes, M.J., R. Sylvester-Bradley, A.J. Worland and J.W.Snape (2004) Effects of a photoperiod-response gene Ppd-D1 on yield potential and drought resistance in UK winter wheat. Euphytica 135: 63-73.

Garner,W.W. and H.A.Allard (1923) Further studies in photoperiodism, the response on the plant to relative length of day and night. J. Agric. Res. 23: 871-920.

Goncharov,N.P. (1986) Genetics of photoperiod response in spring common wheat in connection with breeding for earliness. Ph.D. Thesis, N.I. Vavilov Institute of Plant Industry, Leningrad. 191 p (in Russian).

Goncharov, N.P. (1987) Genetic control of response to photoperiod in common wheat. Res. Bull. N.I.Vavilov Institute of Plant Industry 174: 7-11 (in Russian with English summary).

Goncharov,N.P. and N.N.Chikida (1995) Genetics of growth habit in Aegilops squarrosa. Russ. J. Genet. 31: 343-346.

Gororo, N.N., R.G.Flood, R.F. Eastwood and H.A. Eagles (2001) Photoperiod and vernalization responses in Triticum turgidum $\times$ T. tauschii syntetic hexaploid wheats. Ann. Bot. 88: 947-952.

Halloran, G.M. and C.W.Boydall (1967) Wheat chromosome with genes for photoperiodic response. Can. J. Genet. Cytol. 9: 394398.

Hoogendoorn,J. (1985) A reciprocal $F_{1}$ monosomic analysis of the genetic control of the time of ear-emergence, number of leaves and number of spikelets in wheat (Triticum aestivum L.). Euphytica 34: 545-558.

Islam-Faridi,M.N., A.J.Worland and C.N.Law (1996) Inhibition of ear-emergence time and sensitivity to day-length determined by the group 6 chromosome of wheat. Heredity 77: 572-580.

Keim,D.L., J.R.Welsh and R.L.McConnell (1973) Inheritance of photoperiodic response in winter and spring cultivars of bread wheat. Can. J. Plant Sci. 53: 247-250.

Korzun, V., M.S.Roder, M.W.Ganal, A.J.Worland and C.N.Law (1998) Genetic analysis of the dwarfing gene $R h t 8$ in wheat. I. Molecular mapping of Rht8 in the short arm of chromosome 2D of bread wheat (Triticum aestivum). Theor. Appl. Genet. 96: 1104-1109.

Koshkin,V.A., I.S.Lisker, A.F.Merezhko, I.A.Kosareva, V.A.Dragavtsev 
and I.I.Matvienko (2004) Influence of Ppd genes on phytochrome, photoperiod sensitivity, growth and development of near-isogenic lines. Doklady Russian Acad. Agric. Sci. 1: 3-4 (in Russian with English summary).

Law,C.N., J.Sutka and A.J.Worland (1978) A genetic study of daylength response in wheat. Heredity 41: 185-191.

Law,C.N. and A.J.Worland (1997) Genetic analysis of some flowering time and adaptive traits in wheat. New Phytol. 137: 19-28.

Law,C.N., E.Suarez, T.E.Miller and A.J.Worland (1998) The influence of the group 1 chromosomes of wheat on ear-emergence times and their involvement with vernalization and day length. Heredity 80: 83-91.

Lebsock,K.L., L.R.Joppa and D.E.Welsh (1973) Effect of day length response on agronomic and quality performance of durum wheat. Crop Sci. 13: 670-674.

Martinič,Z. (1973) Vernalization and photoperiodism of common wheat as related to general and specific adaptability of varieties. In 'Proceeding of the Uppsala Symposium 1970' UNESCO. p. 153-163.

Maystrenko,O.I. and E.B.Aliev (1985) Chromosome location of genes for photoperiodic reaction in a non-sensitive spring variety of common wheat Sharbaty Sonora. Cereal Res. Commun. 13: 363-369.

Merezhko,A.F. (1984) Inheritance of the length of "germination-heading" period in spring common wheat hybrids Saratovskaya 29 onto early Mexican cultivars. Tr. Prikl. Bot. Genet. Sel. 85: 30-37 (in Russian with English summary).

Merezhko,A.F. (1994) The problem of donors in plant breeding. N.I.Vavilov Institute of Plant Industry, St.-Petersburg. $128 \mathrm{p}$ (in Russian with English summary).

Murai,K., T.Koba and T.Shimada (1997) Effects of barley chromosome on heading characters in wheat-barley chromosome addition lines. Euphytica 96: 281-287.

Pirasteh,B. and J.R.Welsh (1975) Monosomic analysis of photoperiod response in wheat. Crop Sci. 15: 503-505.

Razumov, V.I. (1961) Environment and plant development. 2nd edn. Selkhozgiz, Moscow, Leningrad. 386 p (in Russian).

Scarth,R. and C.N.Law (1983) The location of the photoperiod gene $P p d 2$, and an additional genetic factor for ear-emergence time on chromosome 2B of wheat. Heredity 51: 607-619.

Scarth,R. and C.N.Law (1984) The control of the day-length response in wheat by the group 2 chromosomes. Zhishr. Pflanzenzücht.
93: $140-150$.

Slafer,G.A. and H.M.Rawson (1995) Photoperiod $\times$ temperature interactions in contrasting wheat genotypes: Time to heading and final leaf number. Field Crops Res. 44: 73-83.

Sourdille,P., M.H.Tixier, G.Charmet, G.Gay, T.Cadalen, S.Bernard and M.Bernard (2000) Location of genes involved in ear compactness in wheat (Triticum aestivum) by means of molecular markers. Mol. Breed. 6: 247-255.

Snape,J.W., S.A.Quarrie and D.A.Laurie (1996) Comparative mapping and its use for the genetic analysis of agronomic characters in wheat. Euphytica 89: 27-31.

Welsh,J.R., D.L.Keim, B.Pirasteh and R.D.Richards (1973) Genetic control of photoperiod response in wheat. In "Proceeding of the 4th International Wheat Genetics Symposium" Sears,E.R. and L.M.S.Sears (eds.), Univ. Missouri, Missouri, USA. p. 879884

Whitechurch,E.M. and G.A.Slafer (2001) Responses to photoperiod before and after jointing in wheat substitution lines. Euphytica 118: 47-51.

Whitechurch,E.M. and G.A.Slafer (2002) Contrasting Ppd alleles in wheat: effects on sensitivity to photoperiod in different phases. Field Crops Res. 73: 95-105.

Worland,A.J., C.N.Law and S.Petrović (1988) Pleiotropic effects of the chromosome 2D genes Ppdl, Rht8 and Yr16. In "Proceeding of the 7th International Wheat Genetics Symposium, 13-19 July. Cambridge, UK” Miller,T.E. and R.M.D.Koebner (eds.), Institute of Plant Science Research, Cambridge, UK. p. 669674

Worland, A.J. and E.Sayers (1996) The influence of flowering time genes on environmental adaptability in European wheats. Euphytica 89: 49-57.

Yoshida,H., M.Kamio and K.Kawaguchi (1983) Evaluation of cultivars for early matureness in the Japanese wheat breeding. In "Proceeding of the 6th International Wheat Genetics Symposium, 20 November-3 December, 1983. Kyoto, Japan" Sakamoto, S. (ed.), Plant Germplasm Institute, Faculty of Agriculture, Kyoto University, Kyoto, Japan. p. 601-612.

Zveinek,S.N. (1983) Genetic control of photoperiod response in intervarietal common wheat substitution lines. Res. Bull. N.I. Vavilov Institute of Plant Industry 163: 17-19 (in Russian with English summary). 